\title{
Article \\ Mechanical Property Improvement in Dissimilar Friction Stir Welded A15083/A16061 Joints: Effects of Post-Weld Heat Treatment and Abnormal Grain Growth
}

\author{
Amir Hossein Baghdadi 1,2 ${ }^{\mathbb{D}}$, Zainuddin Sajuri ${ }^{1, *}$, Azadeh Keshtgar ${ }^{3}$, Nurulakmal Mohd Sharif ${ }^{2}$ \\ and Armin Rajabi ${ }^{1, *(D)}$
}

1 Department of Mechanical and Manufacturing Engineering, Faculty of Engineering and Built Environment, Universiti Kebangsaan Malaysia, UKM, Bangi 43600, Selangor, Malaysia; baghdadi.amirhossein@gmail.com

2 School of Materials \& Mineral Resources Engineering, Engineering Campus, Universiti Sains Malaysia, Nibong Tebal 14300, Pulau Pinang, Malaysia; srnurul@usm.my

3 Center for Risk and Reliability, University of Maryland, College Park, MD 20742, USA; azadeh.keshtgar@gmail.com

* Correspondence: zsajuri@ukm.edu.my (Z.S.); arminrajabi@gmail.com (A.R.); Tel.: +60-(3)-8911-8017 (Z.S.); +60-(3)-8911-8016 (A.R.)

check for updates

Citation: Baghdadi, A.H.; Sajuri, Z.; Keshtgar, A.; Mohd Sharif, N.; Rajabi, A. Mechanical Property Improvement in Dissimilar Friction Stir Welded Al5083/Al6061 Joints: Effects of Post-Weld Heat Treatment and Abnormal Grain Growth. Materials 2022, 15, 288. https:// doi.org/10.3390/ma15010288

Academic Editor: Bolv Xiao

Received: 1 December 2021

Accepted: 27 December 2021

Published: 31 December 2021

Publisher's Note: MDPI stays neutral with regard to jurisdictional claims in published maps and institutional affiliations.

Copyright: (C) 2021 by the authors. Licensee MDPI, Basel, Switzerland. This article is an open access article distributed under the terms and conditions of the Creative Commons Attribution (CC BY) license (https:// creativecommons.org/licenses/by/ $4.0 /)$.

\begin{abstract}
The 5083 and 6061(T6) aluminum (Al) alloys are widely used in transportation industries and the development of structural designs because of their high toughness and high corrosion resistance. Friction stir welding (FSW) was performed to produce the dissimilar welded joint of Al5083-Al 6061(T6) under different welding parameters. However, softening behavior occurred in the friction stir welded (FSWed) samples because of grain coarsening or the dissolution of precipitationhardening phases in the welding zone. Consequently, this research intended to investigate the effect of the post-weld heat treatment (PWHT) method on the mechanical property improvement of the dissimilar FSWed Al5083-Al6061(T6) and governing abnormal grain growth (AGG) through different welding parameters. The results showed PWHT enhanced the mechanical properties of dissimilar joints of Al5083-Al6061(T6). AGG was obtained in the microstructure of PWHTed joints, but appropriate PWHT could recover the dissolved precipitation-hardening particle in the heataffected zone of the as-welded joint. Further, the tensile strength of the dissimilar joint increased from $181 \mathrm{MPa}$ in the as-welded joint to $270 \mathrm{MPa}$ in the PWHTed joint, showing $93 \%$ welding efficacy.
\end{abstract}

Keywords: aluminum alloy; Al6061; Al5083; friction stir welding; heat treatment; abnormal grain growth

\section{Introduction}

Aluminum (Al) alloys are remarkably adaptable materials that are commonly utilized in transportation industries and the development of structural designs [1,2]. Given their moderate strength, commendable toughness features, and high corrosion resistance, Al5083 and Al6061 are ideal for applications related to the automotive industry and fabrication of marine structures, pipelines, and aircraft components [3-5]. Magnesium and silicon are the main alloying elements in the heat-treatable alloy Al6061, whereas magnesium is the only main alloying element in the strain-hardened alloy Al5083 [6,7].

For the combined benefits of different characteristics of various aluminum alloys, dissimilar welding of $\mathrm{Al}$ alloys has received consideration and is increasingly being used in the design of lightweight structures in different industries [8]. Renowned as a versatile solid-state welding method, friction stir welding (FSW) is an alternative process to join Al alloys [9-11]. In FSW, material deformation occurs at a temperature lower than the melting point temperature of joined materials and consequently minimizes distortion and residual stresses in comparison with conventional welding methods [12,13]. Therefore, the issues that arise in the fusion joining of these alloys are absent in FSW [14]. However, a softening behavior or strength reduction also occurs in the welding zone of FSWed Al 
alloys but to a degree that is considerably lower compared with that in fusion welds [15] Softening behavior results from the dissolution or coarsening of precipitation-hardened particles in the heat-affected zone (HAZ) $[16,17]$. The extent of strength reduction in the welding zone during FSW is dependent on the welding parameters applied during the welding process; however, strength reduction occurs despite the application of optimum weld parameters [18-20].

Post-welding processes can be performed on welded samples to improve the loss of strength in the welding of Al alloys by recovering precipitation-hardening particles and relieving residual stress or the average grain size reduction in the weld zone [21]. Hamed [22] carried out the natural aging process on the dissimilar FSWed A17075-A15083. The results showed no noticeable effect on the UTS of the FSWed specimens after 180 days of natural aging. Baghdadi et al. [23] performed T6-PWHT (solutionizing process at 535 ${ }^{\circ} \mathrm{C}$ for $1 \mathrm{~h}$ and artificial aging at $175^{\circ} \mathrm{C}$ for $8 \mathrm{~h}$ ) on the similar FSWed Al6061. PWHT diminished the Portevin-Le Chatelier (PLC) effect that occurred after the welding process and restored the mechanical properties of the welded samples to their original state due to the homogenous distribution of $\mathrm{Mg}_{2} \mathrm{Si}$ particles. Pabandi et al. [24] investigated PWHT on the dissimilar FSWed Al6061-Al2024. A welding efficiency of $80 \%$ was achieved in the PWHTed samples with the emergence of AGG due to solution heat treatments performed at $520{ }^{\circ} \mathrm{C}$. Paidar et al. [25] studied the effect of PWHT (solution heat treatment at $520{ }^{\circ} \mathrm{C}$ for $1 \mathrm{~h}$ and artificial aging at $165^{\circ} \mathrm{C}$ for $18 \mathrm{~h}$ ) on dissimilar FSWed Al2024-A16061. A minor improvement of $13 \mathrm{MPa}$ was obtained in the shear strength of PWHTed samples under optimum welding parameters due to the recovery of the strengthened phases of $\mathrm{Al}_{2} \mathrm{CuMg}$ and $\mathrm{MgZn}_{2}$. Furthermore, Zhang et al. [26] reported the effect of PWHT on dissimilar FSWed Al2024-A17075. The results showed that AGG occurred in the SZ, and the UTS of PWHTed samples was not improved by PWHT due to the lack of mixing of materials in the weld zone.

To date, studies of the effect of heat treatment after the dissimilar FSW of Al5083 and Al6061(T6) are lacking. Therefore, the effect of PWHT on the microstructure and mechanical properties of dissimilar FSWed Al5083-A16061(T6) samples must be comprehensively studied. Accordingly, this research intended to examine the effect of PWHT on the microstructure, mechanical properties, and serration-flow behavior of the stress-strain curves of dissimilar FSWed samples under different welding parameters.

\section{Materials and Methods}

Commercial wrought aluminum alloys of Al6061(T6) and Al5083 were used as base materials (BMs) in this research. Table 1 presents the composition of these alloys and their mechanical properties. The sample size of $150 \times 50 \times 4 \mathrm{~mm}^{3}$ was considered for the dissimilar welding process of Al6061(T6) and Al5083.

Table 1. Chemical compositions and tensile properties of the BMs.

\begin{tabular}{|c|c|c|c|c|c|c|c|c|c|}
\hline \multirow{2}{*}{ Material } & \multicolumn{7}{|c|}{ Chemical Composition (wt. \%) } & \multirow{2}{*}{$\begin{array}{l}\text { Yield Stress } \\
\quad \text { (MPa) }\end{array}$} & \multirow{2}{*}{$\begin{array}{c}\text { Tensile Stress } \\
\text { (MPa) }\end{array}$} \\
\hline & $\mathrm{Al}$ & $\mathrm{Mg}$ & Si & Mn & $\mathrm{Fe}$ & $\mathrm{Cu}$ & $\mathrm{Zn}$ & & \\
\hline Al6061(T6) & Balance & 0.80 & 0.40 & 0.03 & 0.70 & 0.39 & 0.16 & 255 & 290 \\
\hline Al5083-H111 & Balance & 4.46 & 0.25 & 1.00 & 0.45 & - & 0.03 & 202 & 325 \\
\hline
\end{tabular}

Before the welding process, the oxide layers on the surfaces of materials were removed using a steel brush and then washed with acetone. The butt joint configuration was considered in the dissimilar FSW process as shown in Figure 1a. During the FSW process, A15083 was located at the advancing side (AS), and Al6061(T6) was positioned at the retreating side (RS). The H13 tool steel with a length of $3.8 \mathrm{~mm}$ and a shoulder diameter of $20 \mathrm{~mm}$ was used as the FSW tool in the welding process. The FSW tool was tilted by three degrees during the welding process. Table 2 shows the welding parameters and their combinations applied in the welding and PWHT processes. The tool rotational speed 
varied from $800 \mathrm{rpm}$ to $1400 \mathrm{rpm}$, and traveling speeds were set to 100 and $400 \mathrm{~mm} / \mathrm{min}$. Two sets of joints, i.e., as-welded (FSW) and PWHT samples, were produced to investigate the effect of PWHT on the dissimilar welded joint properties. The PWHT process was carried out as follows: solutionizing at $535^{\circ} \mathrm{C}$ for $1 \mathrm{~h}$, quenching in water, and artificial aging at $175{ }^{\circ} \mathrm{C}$ for $8 \mathrm{~h}$.
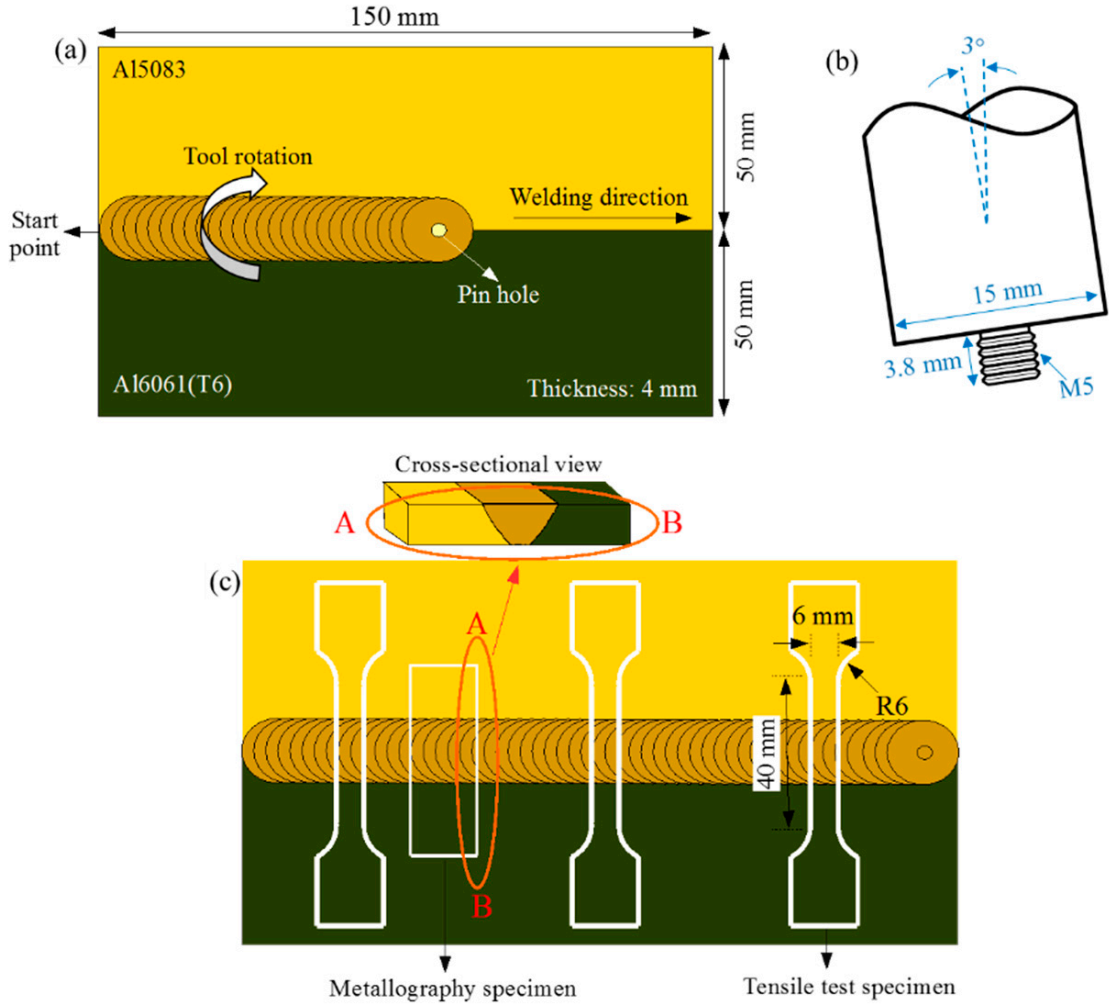

Figure 1. Schematic of the FSW process: (a) configuration of the welding joint, (b) welding tool, and (c) the orientation of samples cutting for microstructure and mechanical testing.

Figure 1c shows the location of the cross-section that was used to observe the microstructure of dissimilar FSWed samples under both conditions. Before the microstructural observation, cold-mounted samples were manually ground by emery papers ranging from \#800 to \#1800. Then, a diamond polishing suspension with a particle size of $1 \mu \mathrm{m}$ was used to polish the samples. The microstructure of the welded samples was revealed via the electrochemical etching method using Barker's reagent at 20 VDC under an optical microscope. The tensile test was performed on a $100 \mathrm{kN}$-capacity Zwick/Roell tensile test machine at room temperature and a strain rate of $10^{-3} \mathrm{~s}^{-1}$ following the ASTM standard E8M-04.

Figure 1c shows the schematic of the tensile test sample. The tensile strength was calculated based on the average of three stress values, and joint efficiency was obtained by dividing the ultimate stress of the welded joint by that of the Al6061(T6)-BM and then multiplying it by $100\left[W_{\text {eff }}=\left(\sigma_{\text {UTS }(\text { Welded })} / \sigma_{\text {UTS }}(\right.\right.$ Al6061(T6) $\left.) \times 100 \%\right]$. A micro-hardness test was performed on the cross-section of dissimilar FSWed samples using A Zwick Vickers hardness (HV) tester with a load of $0.1 \mathrm{kgf}$ and a dwell time of $15 \mathrm{~s}$ per the ASTM standard E384. In addition, field emission scanning electron microscopy (SEM) was used to investigate the fracture modes of the samples after the tensile test. 
Table 2. Sample name and welding parameters of dissimilar joints of Al6061(T6)-Al5083.

\begin{tabular}{cccc}
\hline & Welding Process & PWHT Process \\
\hline Sample Name & $\begin{array}{c}\text { Rotational Speed } \\
(\mathbf{r p m})\end{array}$ & $\begin{array}{c}\text { Travel Speed } \\
\mathbf{( m m / m i n})\end{array}$ & Sample Name \\
\hline Sample A-1 & 800 & 100 & Sample A-1(PWHT) \\
Sample B-1 & 1000 & 100 & Sample B-1(PWHT) \\
Sample C-1 & 1200 & 100 & Sample C-1(PWHT) \\
Sample C-2 & 1200 & 200 & Sample C-2(PWHT) \\
Sample C-3 & 1200 & 300 & Sample C-3(PWHT) \\
Sample C-4 & 1200 & 400 & Sample C-4(PWHT) \\
Sample D-1 & 1400 & 100 & Sample D-1(PWHT) \\
\hline
\end{tabular}

\section{Results and Discussion}

\subsection{Microstructure}

After the welding process, the weld surfaces of the samples were visually inspected to check the welding defects in the welded samples. No welding defects, such as tearing, crack, and porosity, were observed on the weld surfaces. In addition, the weld appearance had smooth semicircular traces with a flash pushed out from the welding zone due to the welding process.

Figure 2 shows the cross-sectional macro photos of the dissimilar joint of Al5083Al6061(T6) under different welding parameters. The macrographs presented no common welding defects, such as crack, porosity, or cavities. Notably, Al5083 was placed in AS, whereas Al601(T6) was located in RS. Three welding zones, namely, SZ, TMAZ, and HAZ, were obtained. The pin penetration was $0.3 \mathrm{~mm}$, and it remained constant under all the welding conditions (Figure 2). SZ in the dissimilar FSW was evident, and the complex structure of Al5083 and Al6061(T6) was demonstrated in the SZ with a flowing shape mostly composed of an AS material (A15083) compared with that in a similar FSWed joint [27,28].
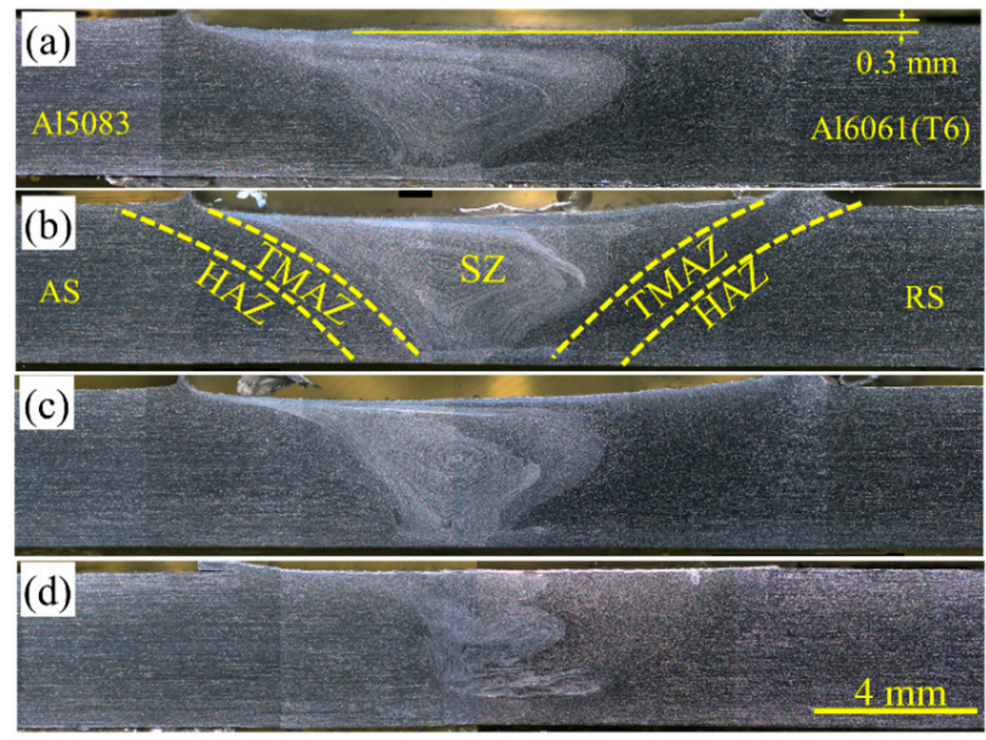

Figure 2. Macro photos of the dissimilar joint of Al5083-Al6061(T6) under different welding parameters; Samples (a) A-1, (b) C-1, (c) D-1, and (d) C-4.

According to the obtained results, a clear borderline was found between SZ and TMAZ at the Al5083 side, whereas no distinct border was observed at the Al6061(T6) side largely because of the reaction of materials with the etching reagent. In other words, the material transported around the tool pin and deposited on the weld line at the RS was notably less than that at AS. The matter was likely formed mostly due to sufficient heat input and stirring impact enhancement, indicating that adequate mixing occurred on AS rather than 
on RS [22,24,29]. Furthermore, the comparison showed that the mixing of materials at SZ was increased by the increased rotational speed from $800 \mathrm{rpm}$ to $1400 \mathrm{rpm}$. This finding may be attributed to the high heat generation and the peak temperature of the samples [22]. In addition, the amount of the dragged material and the mixing of the two BMs in the SZ were decreased by increasing the welding travel speed from $100 \mathrm{~mm} / \mathrm{min}$ to $400 \mathrm{~mm} / \mathrm{min}$.

Figure 3 presents the influence of the FSW process on the welding zone microstructure of welded sample at welding parameters of $1200 \mathrm{rpm}$ and $100 \mathrm{~mm} / \mathrm{min}$. Figure 3a shows the cross-sectional view of the welding zone. The shape of SZ was asymmetric, and SZ was limited by a thin layer of BMs. The Al5083-BM sheet revealed a typical-rolled microstructure of the inhomogeneous grains aligned parallel to RD as presented in Figure $3 \mathrm{~b}$. Moreover, an elongated microstructure was observed in the Al6061(T6)-BM microstructure (Figure 3c). The average grain sizes of 29 and $36 \mu \mathrm{m}$ were obtained for Al5083-BM and Al6061(T6)-BM, respectively.
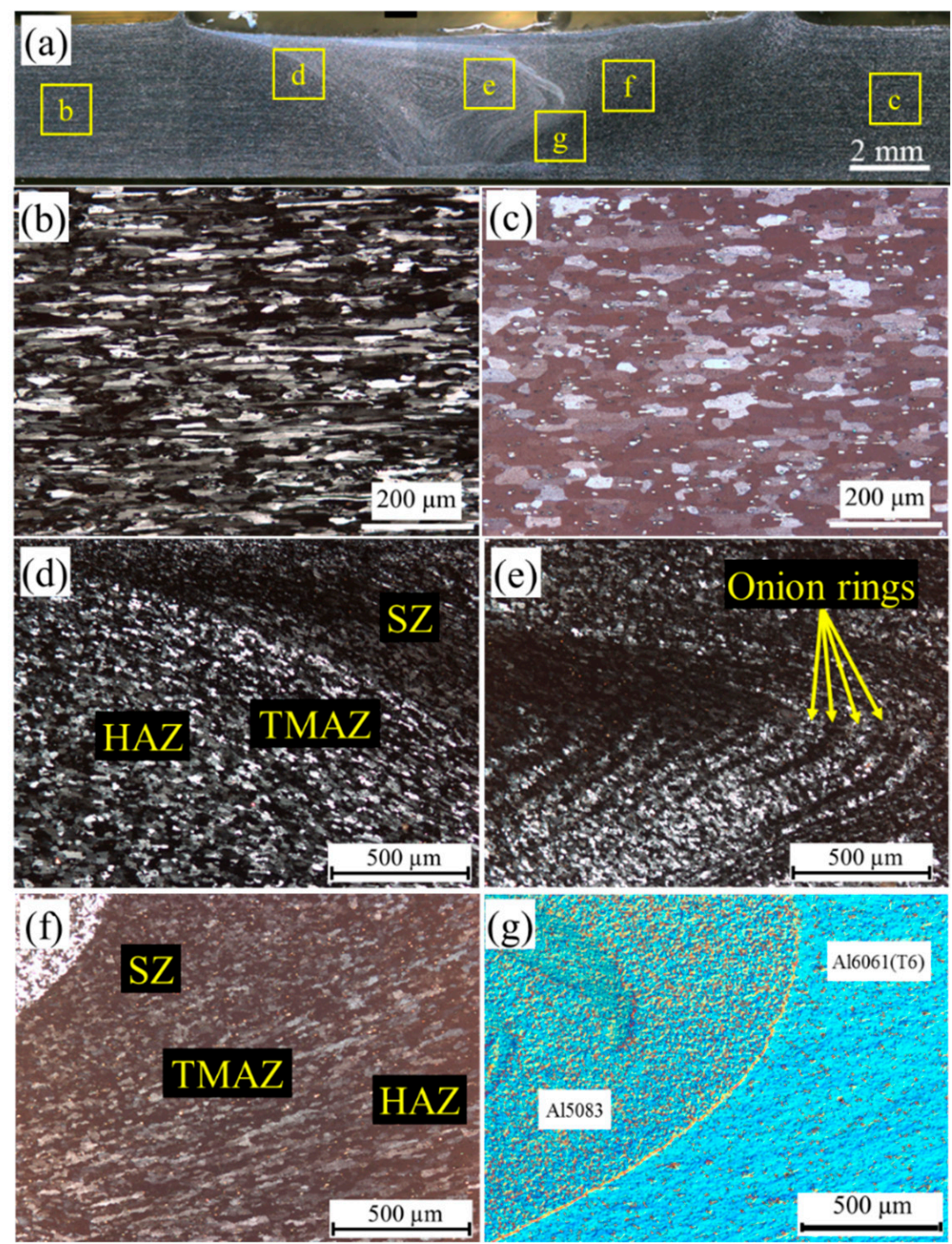

Figure 3. Microstructure of the dissimilar joint of Al5083-Al6061(T6) at Sample C-1; (a) cross-sectional view, (b) Al5083-BM, (c) Al6061(T6)-BM, (d) AS, (e) SZ, (f) RS, and (g) differential interference contrast (DIC) image of SZ.

Figure 3d,f show the high-magnification images of the region (d) at the A15083 side and region (f) at the Al6061(T6) side, respectively. The welding thermal cycle occurred at the HAZ, and no plastic deformation transpired in this zone during the welding process. 
Consequently, the HAZ showed a microstructure similar to the base metal with a large average grain because of the welding heat input $[30,31]$. Figure $3 d$,e illustrate the TMAZ microstructure where the main grains were ringed and stretched in an upward flowing pattern around the nugget. The partial dynamic recrystallization was evaluated at a high strain rate and temperature given that the grains in this zone were strongly deformed.

The SZ revealed a fine grain microstructure because of the mixing of materials directly by the FSW tool. In addition, the SZ exhibited dynamic recrystallization under high temperatures, intense plastic deformation, and a high strain rate applied to materials [32]. Onion ring patterns were detected in the SZ (Figure 3e). Onion rings are described as properly mixed materials in the welding zone during the FSW. The light color was believed to be Al5083, whereas the dark one was Al6061(T6).

Onion rings occur as a result of the ejection of cylindrical sheets of materials in each revolution as they move forward. Given that the influence of tool revolution on materials diminishes in the region away from the weld center, the thickness of bands in an onion ring was large in the center of SZ and thin in the direction of the BMs. Figure $3 \mathrm{~g}$ presents the DIC image of SZ and TMAZ at the RS of the dissimilar joint sample. The border of SZ and TMAZ was evident in RS. This figure distinguishes Al5083 in the mixed microstructure of the SZ and Al6061(T6) in TMAZ at the RS.

After FSW of the dissimilar joint of Al5083-Al6061(T6), the T6 heat treatment included solutionizing and precipitation hardening on the dissimilar FSWed Al5083-Al6061(T6) as PWHT to evaluate its effect on the microstructure and mechanical properties of the joints, which were a complex microstructure of heat-treatable and non-heat-treatable Al alloys. Figure 4 shows the cross-section of PWHTed Al5083-Al6061(T6) under different welding parameters. The welding zone was evident after a PWHT similar to the as-welded condition. Grain growth is a common phenomenon occurring in the welding zone after PWHT. Thus, the microstructure of the PWHTed samples in the welding zones was investigated to evaluate the effects of PWHT under different welding parameters.

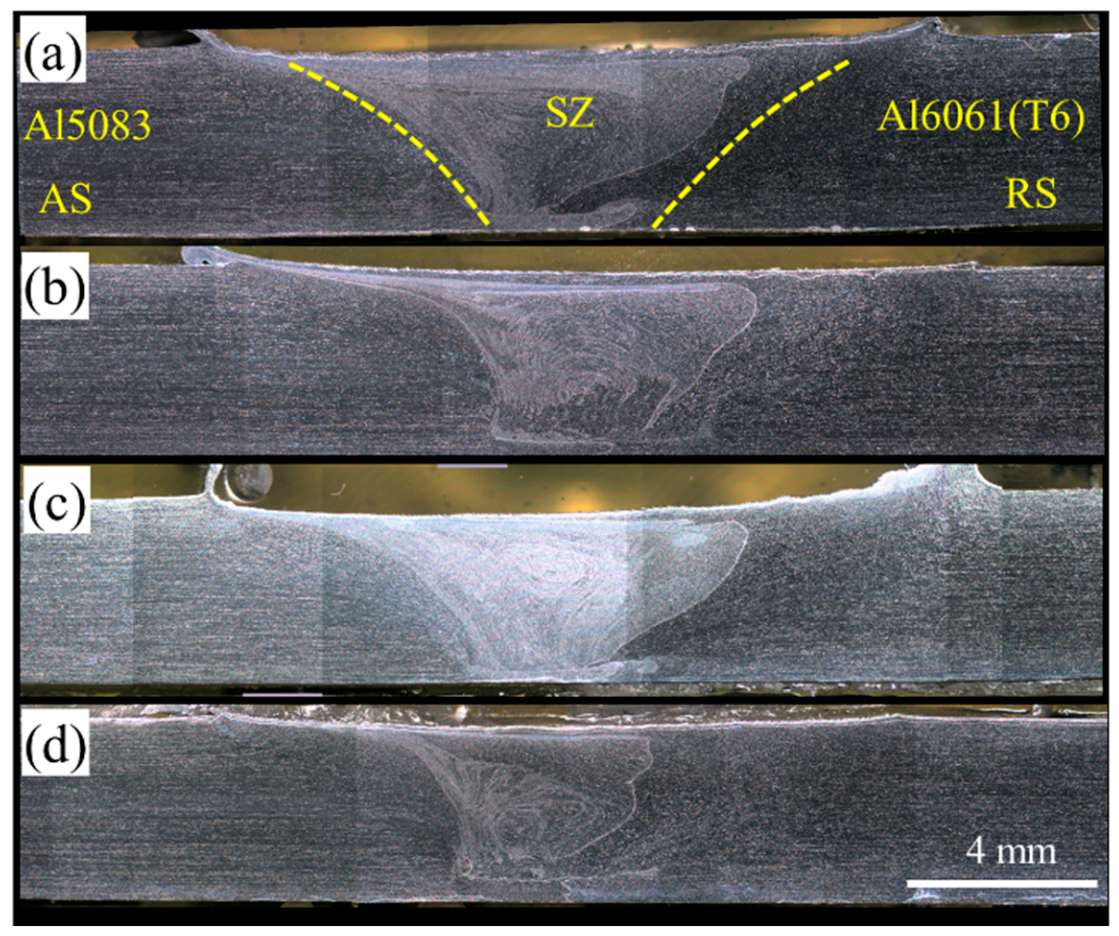

Figure 4. Macro photos of PWHTed Al5083-Al6061(T6) Samples; (a) A-1(PWHT), (b) C-1(PWHT), (c) D-1(PWHT), and (d) C-4(PWHT).

The main effect of PWHT was grain growth in the welding zones. Figure 5 shows the AS, SZ, and RS of the welding zones of the PWHTed samples under different welding 
parameters. The TMAZ on both sides of the welding zone, i.e., AS and RS, was not found in the microstructure of the PWHTed samples compared with that under the asweld condition. The grain size in the SZ increased to several hundred micrometers and millimeters as observed in Figure 5.

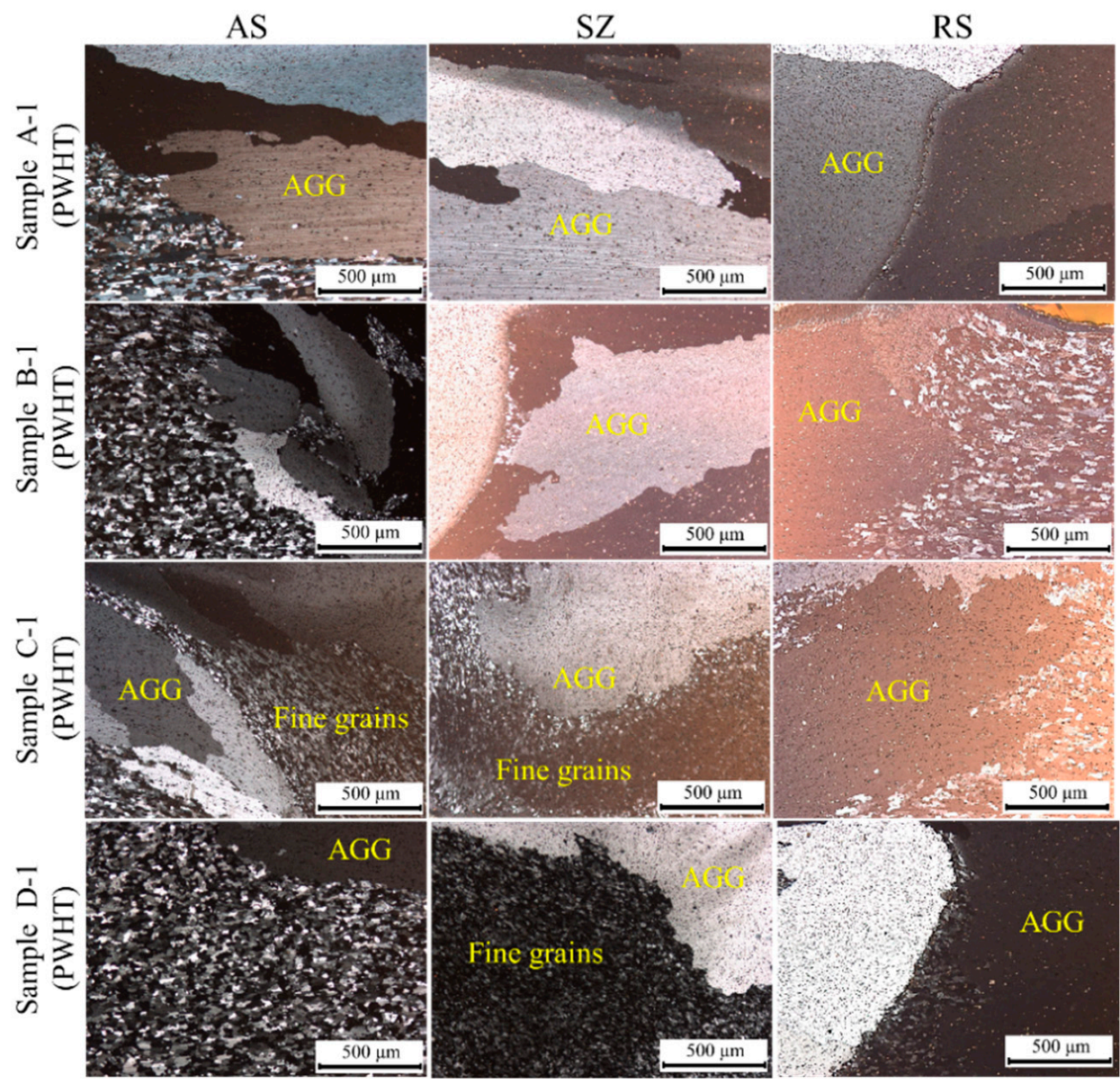

Figure 5. AGG occurs in the microstructure of PWHTed Al5083-16061(T6) at a constant travel speed of $100 \mathrm{~mm} / \mathrm{min}$.

This phenomenon of microstructure instability occurring in the SZ is called AGG. AGG generally occurs when normal grain growth is suppressed [33]. In general, three factors influence the AGG in microstructure: (i) texture effect, i.e., anisotropy in grain boundary energy and mobility; (ii) decrease in pinning effect due to particle dissolution; (iii) nonuniform grain size distribution $[34,35]$. Thus, the balance between the thermodynamic driving force inducing AGG and the pinning force or barrier migration of grain boundaries is a critical feature that should be considered.

The microstructure of SZ was recrystallized and dominated by high-angle grain boundaries due to the random texture distribution in the FSW zone [36]. Variation in energy and mobility between the high-angle grain boundaries did not significantly restart recrystallization when a static high temperature was applied. Furthermore, Mn and Fe, the main elements of the second-phase particles in A15083, were difficult to dissolve in the $\mathrm{Al}$ matrix because the dissolution temperature of these second phases is high; the $\mathrm{Mg}_{2} \mathrm{Si}$ intermetallic compound, which is thermally stable, existed in the SZ $[37,38]$. Thus, these second-phase particles remained unchanged during FSW at different rotational or travel speeds and PWHT at a high temperature (less than $550{ }^{\circ} \mathrm{C}$ ) [39].

PWHT applied to the dissimilar FSWed samples was carried out under the same condition. Therefore, we should focus on the influence of welding parameters, which showed a significant effect on obtaining different microstructures in the welding zones 
due to the variation in heat input and plastic deformation and the presence of different material flows. The SZ was fully covered by AGG in Samples A-1(PWHT) and B-1(PWHT). However, less than a quarter of the thickness of Samples C-1(PWHT) and D-1(PWHT) experienced AGG, and the remaining parts of the welding zone revealed fine grains after PWHT.

AGG was also observed in the PWHTed sample at a constant rotational speed of 1200 rpm, i.e., Samples C-1(PWHT), C-2(PWHT), C-3(PWHT), and C-4(PWHT). The AGG was increased by an increase in the travel speed from $100 \mathrm{~mm} / \mathrm{min}$ in Sample C-1(PWHT) to $400 \mathrm{~mm} / \mathrm{min}$ in Sample C-4(PWHT). The entire thickness of the SZ microstructure underwent AGG in Samples C-3(PWHT) and C-4(PWHT). Moreover, two-thirds of the PWHTed sample exhibited AGG in Sample C-2(PWHT).

Welding parameters influenced the heat input and corresponding thermal cycle. Heat input is inversely related to the weld pitch $(\mathrm{W} / \mathrm{P})$. A low $\mathrm{W} / \mathrm{P}$ corresponds to a high heat input; consequently, AGG occurs to a low extent [40]. In our study, W/P at a welding parameter of $1400 \mathrm{rpm}$ was smaller than that of other FSWed samples (Table 3). The SZ of the PWHTed sample exhibited a low extent of AGG. Moreover, the W/P increased as the travel speed increased at constant rotational speed. Consequently, the SZ of the PWHTed sample slightly experienced AGG at a constant rotational speed of $1200 \mathrm{rpm}$ and travel speed of $100 \mathrm{~mm} / \mathrm{min}$. Therefore, AGG can be controlled by welding parameters, and a good agreement was observed between the revealed microstructure and heat input in the PWHTed Al5083-Al6061(T6) samples.

Table 3. Weld pitch under different welding parameters.

\begin{tabular}{cccc}
\hline Sample & $\begin{array}{c}\text { Welding Rotational } \\
\text { Speed (rpm) }\end{array}$ & $\begin{array}{c}\text { Welding Travel } \\
\text { Speed (mm/min) }\end{array}$ & W/P \\
\hline Sample A-1(PWHT) & 800 & 100 & $1 / 8$ \\
Sample B-1(PWHT) & 1000 & 100 & $1 / 10$ \\
Sample C-1(PWHT) & 1200 & 100 & $1 / 12$ \\
Sample C-2(PWHT) & 1200 & 200 & $1 / 6$ \\
Sample C-3(PWHT) & 1200 & 300 & $1 / 4$ \\
Sample C-4(PWHT) & 1200 & 400 & $1 / 3$ \\
Sample D-1(PWHT) & 1400 & 100 & $1 / 14$ \\
\hline
\end{tabular}

\subsection{Mechanical Properties}

\subsubsection{Tensile Properties}

After the FSW process, a tensile test was performed on the dissimilar joint at the direction normal to the welding direction. Table 4 lists the results of tensile strength of dissimilar joint samples, including UTS, elongation, and joint efficiency, under different welding conditions. In Table 4, the tensile strength was obtained from the average of three stress values, and the joint efficiency was calculated based on the ratio of the UTS of the welded joint to the lower tensile strength of the base materials, i.e., the ultimate stress of Al6061(T6)-BM, multiplied by 100.

The tensile strength and elongation of the dissimilar joint samples were lower than those of BMs. The tensile results showed a reduction of 39\% in FSWed samples compared with the BM due to grain coarsening in the HAZ and over-aging of the strengthening phases in Al6061(T6)-BM. Grain coarsening in the microstructure was the main reason for the strength reduction in FSWed samples and failure at the HAZ of the joint. Different rotational speeds did not significantly affect the tensile strength at a constant travel speed of $100 \mathrm{~mm} / \mathrm{min}$. The highest tensile strength of $181 \mathrm{MPa}$ was obtained in Sample C-1 at a constant travel speed of $100 \mathrm{~mm} / \mathrm{min}$. Zhou et al. [41] reported the highest tensile strength at $1200 \mathrm{rpm}$ amongst the tested rotational speeds because of the existence of a good homogeneous microstructure at a high rotational speed. 
Table 4. Tensile properties of dissimilar FSWed Al5083-Al6061(T6).

\begin{tabular}{cccccc}
\hline Sample & $\begin{array}{c}\text { Ultimate Tensile } \\
\text { Strength (MPa) }\end{array}$ & $\begin{array}{c}\text { Joint } \\
\text { Efficiency } \\
\mathbf{( \% )}\end{array}$ & Sample & $\begin{array}{c}\text { Ultimate Tensile } \\
\text { Strength (MPa) }\end{array}$ & $\begin{array}{c}\text { Joint } \\
\text { Efficiency } \\
\mathbf{( \% )}\end{array}$ \\
\hline A-1 & 173 & 60 & A-1(PWHT) & 231 & 80 \\
B-1 & 177 & 61 & B-1(PWHT) & 232 & 80 \\
C-1 & 181 & 62 & C-1(PWHT) & 235 & 81 \\
C-2 & 193 & 67 & C-2(PWHT) & 270 & 93 \\
C-3 & 202 & 70 & C-3(PWHT) & 267 & 92 \\
C-4 & 207 & 71 & C-4(PWHT) & 265 & 91 \\
D-1 & 176 & 61 & D-1(PWHT) & 229 & 79 \\
\hline
\end{tabular}

However, the UTS of the joint increased by about $14 \%$ by increasing the travel speed from $100 \mathrm{~mm} / \mathrm{min}$ to $400 \mathrm{~mm} / \mathrm{min}$ at a constant rotational speed of $1200 \mathrm{rpm}$. The reason is that less heat was absorbed by the welding zone, leading to the decrease in the average grain size in HAZ due to the increase of travel speed at a constant rotational speed during welding. Saeidi et al. [42] reported that the tensile strength of the dissimilar joint of Al5083 increased as the travel speed increased at constant rotational speeds. As the tensile strength increased, the welding efficiency increased and reached $71 \%$ in Sample C-4. Furthermore, an increase in the travel speed did not significantly affect elongation, which was approximately $5.7 \%$ under all conditions. This decrease in ductility after welding can be attributed to the limited plasticity (i.e., strain concentration) in the joint samples subjected to the tensile test.

Figure 6 presents the stress-strain curves of the dissimilar FSWed, PWHTed, Al5083BM, and A16061(T6) samples. The PLC effect was observed as a serration behavior in the dissimilar joints before $\sigma_{U T S}$, as pointed by the arrow in Figure 6, due to plastic instability during the tensile test $[23,43]$. The PLC effect is due to transient interactions between mobile clouds of impurities (diffusing solute atoms) and glide dislocations [44]. An Mg atom containing Al5083 is larger than an Al atom in the Al matrix, thereby hindering the dislocation movement and increasing the strength of an $\mathrm{Al}$ alloy [45]. As a result, the PLC effect is linked to pinning and unpinning, whereas a pinned process occurs when barriers made from forest dislocations and grain boundaries prevent the movement of dislocation. Conversely, an unpinned process and a decrease in stress during the tensile test occur when dislocation can be overcome from the solute cloud [46]. Figure 6 shows the stress-strain curve of Sample C-4(PWHT) as a function of PWHT at a rotational speed of $1400 \mathrm{rpm}$.

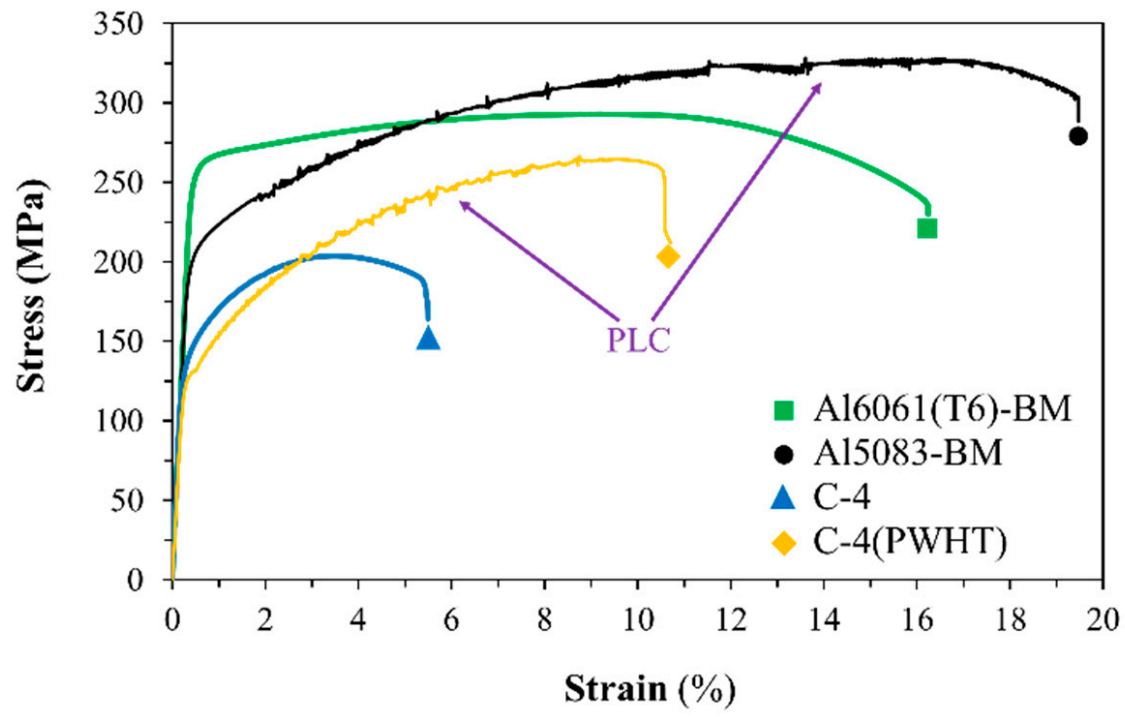

Figure 6. Tensile properties of FSWed and PWHTed of the Al5083-Al6061(T6) dissimilar joint. 
The PWHT improved the mechanical properties and increased the ductility of the dissimilar joint of Al5083-Al60661(T6) samples. However, the microstructure of the PWHTed samples had an elongated grain and a prolonged AGG in the welding zones. These observations were different from the mechanical properties obtained after PWHT. According to the well-known Hall-Petch equation, the tensile strength should decrease as the grain size increases. Recent studies reported that the effect of second-phase particle distribution on the mechanical properties of the Al5083 FSWed joint should be considered rather than grain size [24,41]. Thus, an increase in the tensile properties of the PWHTed samples can be attributed to the formation of precipitation-hardening particles, especially in Al6061(T6), which were recovered after PWHT.

Table 4 shows the effect of PWHT on the tensile properties of the dissimilar joint of A15083-A16061(T6) compared with that of the dissimilar FSWed joint. The maximum ultimate stress of $235 \mathrm{MPa}$ was achieved with an elongation of 7.1\% in Sample C-1(PWHT). Thus, the welding efficiency changed from $62 \%$ under the as-welded condition to $81 \%$ for Sample C-1(PWHT). Further, the tensile properties increased as the travel speed increased from $100 \mathrm{~mm} / \mathrm{min}$ to $400 \mathrm{~mm} / \mathrm{min}$ possibly because of the good mixing of A15083 and Al6061(T6) at a low heat input and the precipitation hardening effect after PWHT in the SZ. In addition, the yield stress of $163 \mathrm{MPa}$ and maximum tensile strength of $270 \mathrm{MPa}$ were achieved in Sample C-2(PWHT).

From the results presented, PWHT is a beneficial post-welding process that can recover and improve the mechanical properties of FSWed heat-treatable Al6061 alloys. However, as discussed in the previous section, the critical problem of PWHT is grain growth or AGG in the microstructure of the PWHTed sample. AGG can affect the mechanical and fatigue properties of the FSWed samples for engineering structure applications. However, in this study, by controlling the welding parameters, i.e., the rotational speed at $1200 \mathrm{rpm}$ and the travel speed at $200 \mathrm{~mm} / \mathrm{min}$, the AGG effect was suppressed and cancelled out by precipitation hardening from the T6 heat treatment, which resulted in the increased ultimate strength of the joint from $181 \mathrm{MPa}$ to $270 \mathrm{MPa}$ at $93 \%$ welding efficiency.

\subsubsection{Fractography}

Figure 7 presents the fracture location of the dissimilar FSWed samples under different welding parameters. Fracture and necking occurred at the HAZ of Al6061(T6) in all the dissimilar joint samples. The overview of fracture location confirmed that it was outside the welding zone (Figure 7). The PWHTed samples exhibited the necking phenomenon at the fracture location. Notably, fracture and necking occurred at the interface of Al5083 and Al6061(T6) in the SZ. This finding showed that the fracture location moved from the HAZ in the as-welded samples to SZ in the PWHTed samples due to PWHT. The stress-strain curve behavior was attributed to the moving failure position (Figure 6).

The mechanism of the serration flow behavior of dissimilar joints can be clarified and specified after the tensile test by checking the failure position in the dissimilar joint, which occurred in the HAZ at the RS and SZ in FSWed and PWHTed samples, respectively. However, the stress-strain curve behavior of the PWHTed Al5083-Al6061(T6) samples was different from that under the as-weld condition in terms of serration flow in the plastic region. The serration flow behavior of the PWHTed Al5083-Al6061(T6) samples was similar to that of A15083-BM, which presented a severe serration flow behavior on the stress-strain curve due to the shifting of fracture location from RS to SZ toward the A15083 side in PWHTed samples. 


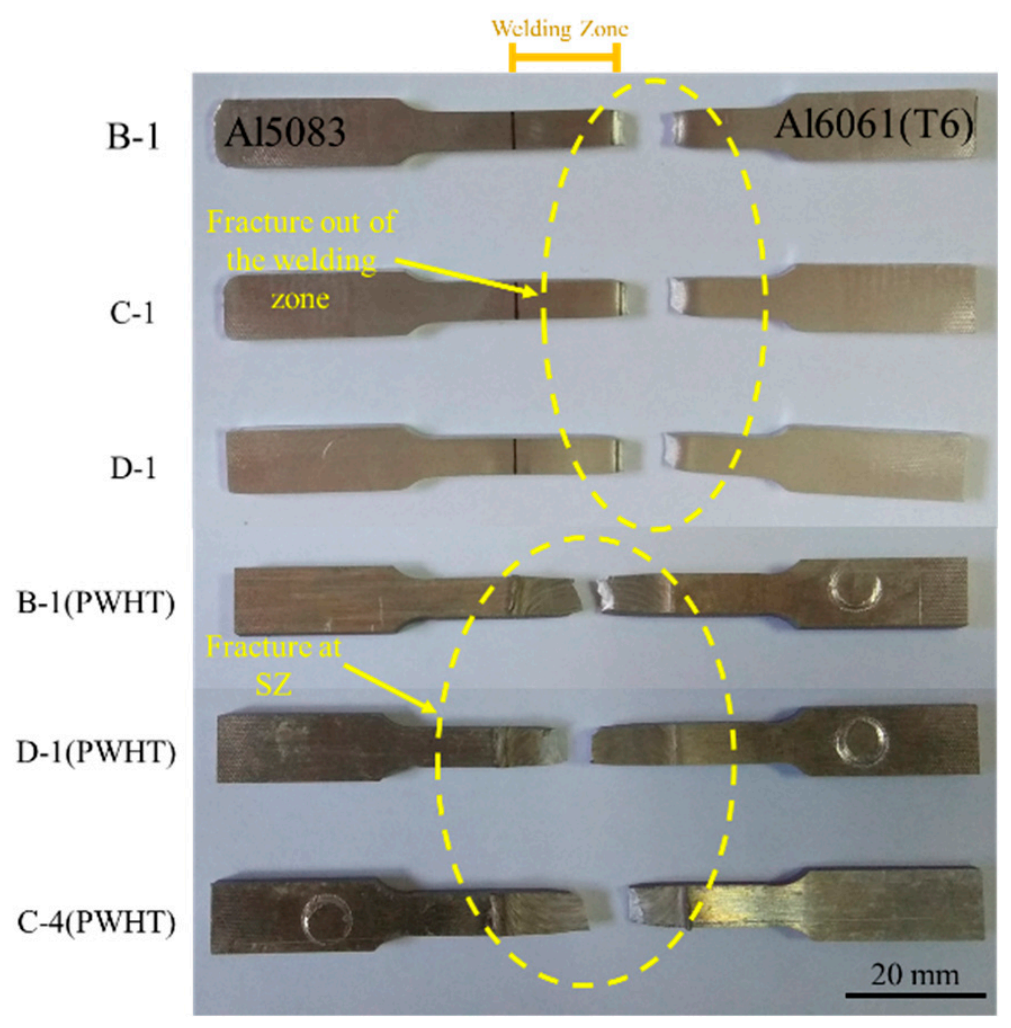

Figure 7. Fracture location of the dissimilar joint of Al5083-Al6061(T6) after the tensile test.

\subsection{Hardness Profile}

The hardness (HV) distribution profile was determined to evaluate the hardness properties of the dissimilar joint of A15083-Al6061(T6) samples under different welding parameters (Figure 8). The hardness profile of the dissimilar joint samples had the same behavior under as-welded conditions. In addition, a fluctuating hardness distribution profile was obtained from the dissimilar joint samples corresponding to three distinct welding zones, namely, SZ, TMAZ, and HAZ.

The lowest HVs were detected at the HAZ adjacent to TMAZ on the RS, in which Al6061(T6) was placed on that side under all welding conditions. The lowest hardness values of 52, 55, 60, and $57 \mathrm{HV}$ (Figure 8a) were obtained at rotational speeds of 800, 1000, 1200, and $1400 \mathrm{rpm}$, respectively. The measured HVs of Al6061(T6)-BM and Al5083-BM ranged from 93 to 97 and from 92 to 95, respectively. In general, the hardness properties in the welding zone of the dissimilar joint samples decreased compared with those of BMs, i.e., Al5083-BM and Al6061(T6)-BM, under different welding parameters. The plate underwent coarsening and solutionizing of the strengthening elements during welding. In addition, HAZ experienced the over-aging caused by the coarsening of strengthening elements due to heat input during the joining process. Thus, these cases caused a reduction in the hardness in the welding zones, especially in RS, which was heat-treatable Al6061(T6). This result is consistent with the failed dissimilar joint samples after the tensile tests, in which the fracture location was placed in HAZ due to a low hardness value.

In PWHTed samples, the hardness profile was obtained with the same behavior, showing that the hardness properties were improved by PWHT (Figure 8b). Notably, the improvement of hardness properties was significant in the RS, which was Al6061(T6). The hardness properties of Al6061(T6) were enhanced because of the homogeneous distribution of precipitation hardening after PWHT [47]. However, the hardness properties of Al5083 decreased in AS because of the coarsening of the hard particle and grain growth in BM. With AGG in the welding zone after PWHT, the hardness test of the PWHTed samples showed that precipitation hardening was the main factor that increased the strength of A6061(T6) rather than the average grain size. Thus, a good agreement was observed between the 
results of the tensile and hardness tests. The hardness profile of the PWHTed samples showed the same properties with low fluctuation on BMs, and the lowest hardness value was located at the interface of the PWHTed samples. The fracture location of the PWHTed samples occurred at the interface of the SZ. This finding was consistent with the results obtained via the hardness test.

(a)

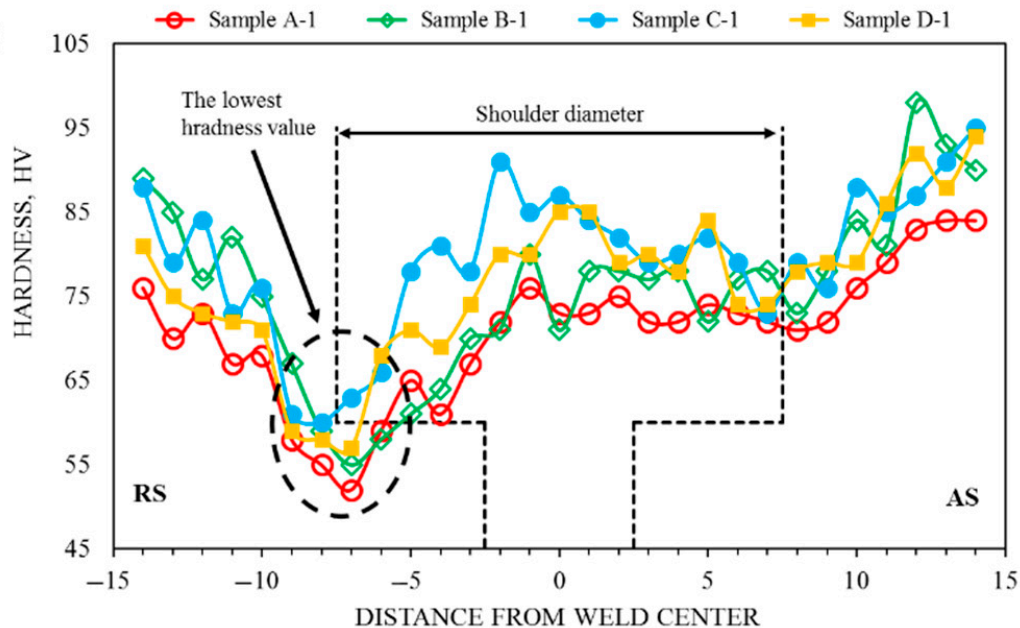

(b)

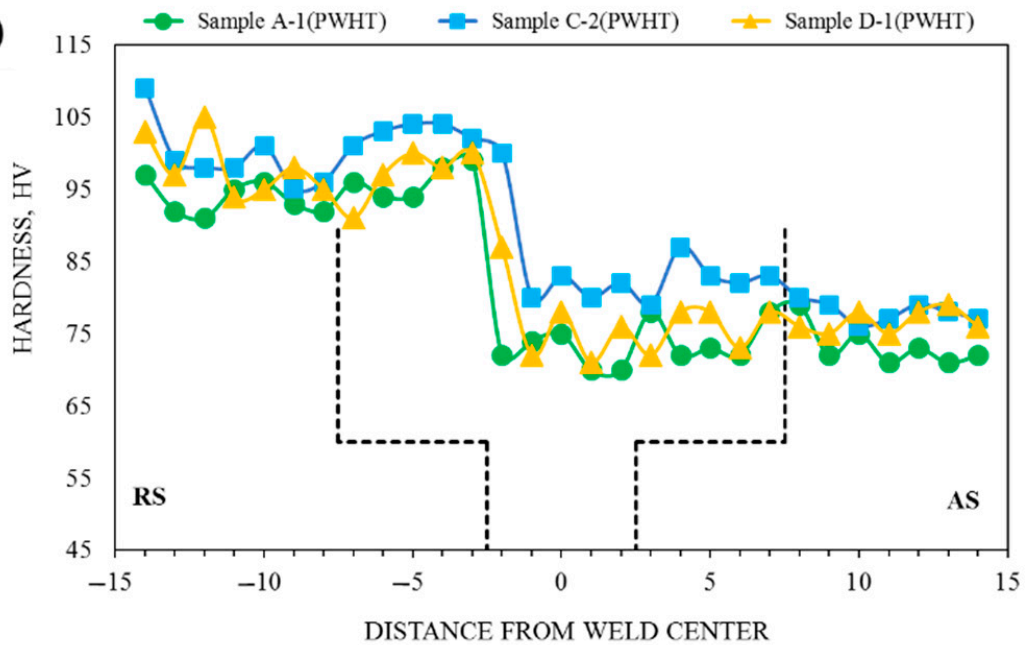

Figure 8. Hardness profile of the dissimilar joint of Al5083-Al6061(T6); (a) as-welded and (b) PWHTed conditions. The black dotted line is the tool pin profile.

\section{Conclusions}

This study was performed to investigate the effect of PWHT and FSW parameters on microstructure and mechanical properties of dissimilar joints of Al5083-Al6061(T6). The conclusions obtained from the investigation are summarized below.

1. Sound joints were obtained with no welding defects, such as cracks, porosity, and tunnel, under various welding parameters. The highest joint efficiency was obtained from Sample C-4 (1200 rpm and $400 \mathrm{~mm} / \mathrm{min}$ ) with a value of $71 \%$. A decrease in the weld strength was observed in the as-welded samples due to the dissolution of precipitation hardening particles in the HAZ at RS, which was Al6061(T6).

2. By controlling the welding parameters, i.e., the rotational speed at $1200 \mathrm{rpm}$ and the travel speed at $200 \mathrm{~mm} / \mathrm{min}$ (Sample C-2 (PWHT)), the AGG effect was suppressed and cancelled out by the homogeneous distribution of precipitation hardening phases in the welding zone from the appropriate T6 heat treatment, which resulted in the increased ultimate strength of the joint from $181 \mathrm{MPa}$ in the as-welded joint to 270 $\mathrm{MPa}$ in PWHTed joint at 93\% welding efficiency. 
3. The hardness properties were improved from $55 \mathrm{HV}$ in the as-welded joint to $95 \mathrm{HV}$ in PWHTed joint due to homogeneous distribution of precipitation hardening phases in the welding zone after PWHT, which caused a shifting of the fracture location from HAZ at RS in the as-welded joint to SZ of PWHTed joint after the tensile test.

Author Contributions: Conceptualization, A.H.B.; Formal analysis, A.H.B. and A.K.; Investigation, A.H.B.; Methodology, A.H.B. and Z.S.; Project administration, Z.S.; Supervision, Z.S. and N.M.S.; Visualization, A.H.B. and A.R.; Writing-original draft, A.H.B.; Writing—review \& editing, Z.S., A.K., N.M.S. and A.R. All authors have read and agreed to the published version of the manuscript.

Funding: This research was funded by Universiti Kebangsaan Malaysia, grant number DIP-2021-005 and GGPM-2021-009.

Institutional Review Board Statement: Not applicable.

Informed Consent Statement: Not applicable.

Conflicts of Interest: The authors declare no conflict of interest.

\section{References}

1. Peng, P.; Wang, W.; Zhang, T.; Liu, Q.; Guan, X.; Qiao, K.; Cai, J.; Wang, K. Effects of interlayer metal on microstructures and mechanical properties of friction stir lap welded dissimilar joints of magnesium and aluminum alloys. J. Mater. Process. Technol. 2022, 299, 117362. [CrossRef]

2. Liu, X.; Jia, R.; Zhang, H.; Cheng, W.; Zhai, X. EBSD Characterization of the Microstructure of 7A52 Aluminum Alloy Joints Welded by Friction Stir Welding. Materials 2021, 14, 6362. [CrossRef]

3. Naumov, A.; Rylkov, E.; Polyakov, P.; Isupov, F.; Rudskoy, A.; Aoh, J.-N.; Popovich, A.; Panchenko, O. Effect of Different Tool Probe Profiles on Material Flow of Al-Mg-Cu Alloy Joined by Friction Stir Welding. Materials 2021, 14, 6296. [CrossRef]

4. Jayaseelan, V.; Jayabalakrishnan, D.; Ashok Gandhi, R.; Muthuramalingam, T.; Francis Xavier, J. Impact of the novel square wave tool path pattern on AA6061-T6 friction stir welding. Mater. Manuf. Process. 2021, 36, 1-10. [CrossRef]

5. Baghdadi, A.H.; Sajuri, Z.; Mohamad Selamat, N.F.; Omar, M.Z.; Miyashita, Y.; Kokabi, A.H. Effect of intermetallic compounds on the fracture behavior of dissimilar friction stir welding joints of $\mathrm{Mg}$ and $\mathrm{Al}$ alloys. Int. J. Miner. Metall. Mater. 2019, 26, 1285-1298. [CrossRef]

6. Selamat, N.M.; Baghdadi, A.H.; Sajuri, Z.; Kokabi, A.H.; Junaidi, S. Effect of rolling on strength of friction stir welded joint of aluminium alloys. J. Kejuruter. 2018, 1, 9-15.

7. Gao, S.; Zhou, L.; Sun, G.; Zhao, H.; Chu, X.; Li, G.; Zhao, H. Influence of Welding Speed on Microstructure and Mechanical Properties of 5251 Aluminum Alloy Joints Fabricated by Self-Reacting Friction Stir Welding. Materials 2021, 14, 6178. [CrossRef]

8. Chen, L.; Wang, C.; Xiong, L.; Zhang, X.; Mi, G. Microstructural, porosity and mechanical properties of lap joint laser welding for 5182 and 6061 dissimilar aluminum alloys under different place configurations. Mater. Des. 2020, 191, 108625. [CrossRef]

9. Toursangsaraki, M.; Li, Q.; Hu, Y.; Wang, H.; Zhao, D.; Zhao, Y. Crystal plasticity modeling for mechanical property prediction of AA2195-T6 friction stir welded joints. Mater. Sci. Eng. A 2021, 823, 141677. [CrossRef]

10. Manuel, N.; Beltrão, D.; Galvão, I.; Leal, R.M.; Costa, J.D.; Loureiro, A. Influence of Tool Geometry and Process Parameters on Torque, Temperature, and Quality of Friction Stir Welds in Dissimilar Al Alloys. Materials 2021, 14, 6020. [CrossRef]

11. You, J.; Zhao, Y.; Dong, C.; Miao, S.; Liu, Z.; Liu, L.; Su, Y. Microstructural evolution and mechanical properties of the Al-Cu dissimilar joint enhanced by stationary-dynamic shoulder friction stir welding. J. Mater. Process. Technol. 2022, $300,117402$. [CrossRef]

12. Zhang, H.; Chen, S.; Zhang, Y.; Chen, X.; Li, Z.; Yang, Z. Effect of High Rotational-Speed Friction-Stir Welding on Microstructure and Properties of Welded Joints of 6061-T6 Al Alloy Ultrathin Plate. Materials 2021, 14, 6012. [CrossRef]

13. Ghavimi, A.H.; Aboutalebi, M.R.; Seyedein, S.H. Exit-hole repairing in friction stir welding of AA5456 pipe using consumable pin. Mater. Manuf. Process. 2020, 35, 1240-1250. [CrossRef]

14. Kumar, N.; Mishra, R.S.; Yuan, W. Friction Stir Welding of Dissimilar Alloys and Materials; Butterworth-Heinemann: Oxford, UK, 2015; ISBN 9780128024188.

15. Pakdil, M.; Çam, G.; Koçak, M.; Erim, S. Microstructural and mechanical characterization of laser beam welded AA6056 Al-alloy. Mater. Sci. Eng. A 2011, 528, 7350-7356. [CrossRef]

16. Osman, N.; Sajuri, Z.; Baghdadi, A.H.; Omar, M.Z. Effect of Process Parameters on Interfacial Bonding Properties of AluminiumCopper Clad Sheet Processed by Multi-Pass Friction Stir-Welding Technique. Metals 2019, 9, 1159. [CrossRef]

17. Ahmed, S.; Verma, M.; Saha, P. Process responses during $\mu$ FSW of AA6061-T6 under the influence of triple-spiral micro-grooves on shoulder end-surface. J. Mater. Process. Technol. 2021, 290, 116984. [CrossRef]

18. Memon, S.; Murillo-Marrodán, A.; Lankarani, H.M.; Aghajani Derazkola, H. Analysis of Friction Stir Welding Tool Offset on the Bonding and Properties of Al-Mg-Si Alloy T-Joints. Materials 2021, 14, 3604. [CrossRef] 
19. Wenjing, Y.; Hua, D.; Jizhong, L. Parametric optimization for friction stir processing in Al-Zn-Mg-Cu alloy. Mater. Manuf. Process. 2021, 36, 1-10. [CrossRef]

20. Baghdadi, A.H.; Sajuri, Z.; Omar, M.Z.; Rajabi, A. Friction Stir Welding Parameters: Impact of Abnormal Grain Growth during Post-Weld Heat Treatment on Mechanical Properties of Al-Mg-Si Welded Joints. Metals 2020, 10, 1607. [CrossRef]

21. Ogunsemi, B.T.; Abioye, T.E.; Ogedengbe, T.I.; Zuhailawati, H. A review of various improvement strategies for joint quality of AA 6061-T6 friction stir weldments. J. Mater. Res. Technol. 2021, 11, 1061-1089. [CrossRef]

22. Hamed, J.A. Effect of welding heat input and post-weld aging time on microstructure and mechanical properties in dissimilar friction stir welded AA7075-AA5086. Trans. Nonferr. Met. Soc. China 2017, 27, 1707-1715. [CrossRef]

23. Baghdadi, A.H.; Rajabi, A.; Mohamad Selamat, N.F.; Sajuri, Z.; Omar, M.Z. Effect of post-weld heat treatment on the mechanical behavior and dislocation density of friction stir welded Al6061. Mater. Sci. Eng. A 2019, 754, 728-734. [CrossRef]

24. Pabandi, H.K.; Jashnani, H.R.; Paidar, M. Effect of precipitation hardening heat treatment on mechanical and microstructure features of dissimilar friction stir welded AA2024-T6 and AA6061-T6 alloys. J. Manuf. Process. 2018, 31, 214-220. [CrossRef]

25. Paidar, M.; Tahani, K.; Vaira Vignesh, R.; Ojo, O.O.; Ezatpour, H.R.; Moharrami, A. Modified friction stir clinching of 2024-T3 to 6061-T6 aluminium alloy: Effect of dwell time and precipitation-hardening heat treatment. Mater. Sci. Eng. A 2020, $791,139734$. [CrossRef]

26. Zhang, C.; Huang, G.; Cao, Y.; Li, Q.; Zhu, Y.; Huang, X.; Liu, Q. Investigation on microstructure and localized corrosion behavior in the stir zone of dissimilar friction-stir-welded AA2024/7075 joint. J. Mater. Sci. 2020, 55, 15005-15032. [CrossRef]

27. Wang, B.; Lei, B.; Zhu, J.; Feng, Q.; Wang, L.; Wu, D. EBSD study on microstructure and texture of friction stir welded AA5052-O and AA6061-T6 dissimilar joint. Mater. Des. 2015, 87, 593-599. [CrossRef]

28. Baghdadi, A.H.; Selamat, N.F.M.; Sajuri, Z.; Kokabi, A.H. Effect of travel speed on quality and welding efficiency of friction stir welded AZ31B magnesium alloy. Int. J. Eng. Technol. (UAE) 2018, 7, 94-99. [CrossRef]

29. Selamat, N.F.M.; Baghdadi, A.H.; Sajuri, Z.; Kokabi, A.H. Weldability and mechanical properties of dissimilar al-mgsi to pure aluminium and al-mg using friction stir welding process. J. Teknol. 2019, 81, 143-149. [CrossRef]

30. $\mathrm{Xu}, \mathrm{W} . ; \mathrm{Liu}, \mathrm{J} . ; \mathrm{Zhu}, \mathrm{H} . ; \mathrm{Fu}, \mathrm{L}$. Influence of welding parameters and tool pin profile on microstructure and mechanical properties along the thickness in a friction stir welded aluminum alloy. Mater. Des. 2013, 47, 599-606. [CrossRef]

31. Selamat, N.F.M.; Baghdadi, A.H.; Sajuri, Z.; Junaidi, S.; Kokabi, A.H. Rolling effect on dissimilar friction stir welded AA5083AA6061 aluminium alloy joints. J. Adv. Manuf. Technol. (JAMT) 2020, 14, 49-61.

32. Akbari, R.; Mirdamadi, S.; Khodabandeh, A.; Paidar, M. A study on mechanical and microstructural properties of dissimilar FSWed joints of AA5251-AA5083 plates. Int. J. Mater. Res. 2016, 107, 752-761. [CrossRef]

33. Humphreys, F.J. A unified theory of recovery, recrystallization and grain growth, based on the stability and growth of cellular microstructures-I. The basic model. Acta Mater. 1997, 45, 4231-4240. [CrossRef]

34. García-Bernal, M.A.; Mishra, R.S.; Verma, R.; Hernández-Silva, D. Inhibition of abnormal grain growth during hot deformation behavior of friction stir processed 5083 Al alloys. Mater. Sci. Eng. A 2015, 636, 326-330. [CrossRef]

35. Humphreys, F.J.; Hatherly, M. Recrystallization and Related Annealing Phenomena; Elsevier: Oxford, UK, 2004; ISBN 008098388X.

36. Gottstein, G. Physical Foundations of Materials Science; Springer Science \& Business Media: New York, NY, USA, 2013; ISBN 9783662092910

37. Chen, Y.; Ding, H.; Li, J.; Cai, Z.; Zhao, J.; Yang, W. Influence of multi-pass friction stir processing on the microstructure and mechanical properties of Al-5083 alloy. Mater. Sci. Eng. A 2016, 650, 281-289. [CrossRef]

38. Chen, K.E.; Gan, W.; Okamoto, K.; Chung, K.; Wagoner, R.H. The mechanism of grain coarsening in friction-stir-welded AA5083 after heat treatment. Metall. Mater. Trans. A 2011, 42, 488-507. [CrossRef]

39. García-Bernal, M.A.; Mishra, R.S.; Verma, R.; Hernández-Silva, D. Influence of friction stir processing tool design on microstructure and superplastic behavior of Al-Mg alloys. Mater. Sci. Eng. A 2016, 670, 9-16. [CrossRef]

40. Charit, I.; Mishra, R.S. Abnormal grain growth in friction stir processed alloys. Scr. Mater. 2008, 58, 367-371. [CrossRef]

41. Zhou, N.; Song, D.; Qi, W.; Li, X.; Zou, J.; Attallah, M.M. Influence of the kissing bond on the mechanical properties and fracture behaviour of AA5083-H112 friction stir welds. Mater. Sci. Eng. A 2018, 719, 12-20. [CrossRef]

42. Saeidi, M.; Manafi, B.; Besharati Givi, M.K.; Faraji, G. Mathematical modeling and optimization of friction stir welding process parameters in AA5083 and AA7075 aluminum alloy joints. Proc. Inst. Mech. Eng. Part B J. Eng. Manuf. 2016, 230, 1284-1294. [CrossRef]

43. Sajuri, Z.; Selamat, N.F.M.; Baghdadi, A.H.; Rajabi, A.; Omar, M.Z.; Kokabi, A.H.; Syarif, J. Cold-rolling strain hardening effect on the microstructure, serration-flow behaviour and dislocation density of friction stir welded AA5083. Metals 2020, 10, 70. [CrossRef]

44. Van den Beukel, A. Theory of the effect of dynamic strain aging on mechanical properties. Phys. Status Solidi (A) 1975, 30, 197-206. [CrossRef]

45. Verdier, M.; Janecek, M.; Brechet, Y.; Guyot, P. Microstructural evolution during recovery in Al-2.5\% Mg alloys. Mater. Sci. Eng. A 1998, 248, 187-197. [CrossRef]

46. Fu, S.; Zhang, Q.; Hu, Q.; Gong, M.; Cao, P.; Liu, H. The influence of temperature on the PLC effect in Al-Mg alloy. Sci. China Technol. Sci. 2011, 54, 1389-1393. [CrossRef]

47. Malopheyev, S.; Vysotskiy, I.; Kulitskiy, V.; Mironov, S.; Kaibyshev, R. Optimization of processing-microstructure-properties relationship in friction-stir welded 6061-T6 aluminum alloy. Mater. Sci. Eng. A 2016, 662, 136-143. [CrossRef] 